\title{
Crack Growth in FeP04 Steel under Cyclic Tension for Different Notches on the Basis of its Microstructure
}

\author{
D. Rozumek ${ }^{1, a}$ \\ ${ }^{1}$ Opole University of Technology, Department of Mechanics and Machine Design, Opole, Poland \\ a d.rozumek@po.opole.pl
}

We present the results of experimental work carried out in order to analyze the initiation and propagation of fatigue cracks in FeP04 steel. The tests were performed in plane specimens under cyclic tension by keeping constant the nominal load ratio $R=0$. Crack paths on the basis of the tested material microstructure were observed.

Keywords: crack path, microstructure, fatigue crack growth rate, notches, $J$-integral range.

Introduction. In steels and alloys, two basic crack growth mechanisms can be distinguished: brittle and ductile [1]. In case of brittle cracking, intercrystalline cracking (so-called fissile cracking) is usually observed. For ductile cracking, disintegration of the specimen surface in pure metals is caused by successive slip bands; in commercial alloys cracking begins in harder elements (non-metallic inclusions), where the developing voids cause failure. During fatigue crack growth in metal alloys, the following three stages can be distinguished [2]. The first stage includes generation of microcracks or formation of voids and is connected with phenomena occurring in the dislocation structure of the material. The second stage includes crack growth in the plane of maximum principal stresses. The final fracture causes the growing crack to reach its critical length, or the stress reaches the tensile strength level, and the element fails.

The aim of this study is determination of the fatigue crack growth in FeP04 steel, used in car industry, taking into account the influence of microstructure and different notches on the steel life (fatigue crack growth rate).

Materials and Test Procedure. Static Properties and Fatigue Tests of Notched Specimens. Tests were carried out on plates made of FeP04-UNI 8092 deep-drawing steel, weakened by symmetric lateral notches of varying acuity. The tests were performed using a MTS 809 servo-hydraulic device at the Department of Management and Engineering in Vicenza (Padova University) [3]. Chemical composition (wt.\%) of the FeP04 steel tested are $0.05 \mathrm{C}, 0.30 \mathrm{Mn}, 0.05 \mathrm{Si}, 0.032 \mathrm{P}, 0.02 \mathrm{~S}, 0.043 \mathrm{Al}$, and $0.07 \mathrm{Cu}$. Mechanical properties of FeP04 steel are as follows: $\sigma_{y}=210 \mathrm{MPa}, \sigma_{u}=330 \mathrm{MPa}, E=191 \mathrm{GPa}$, $v=0.3$. Coefficients of the Ramberg-Osgood equation describing the cyclic strain curve under tension-compression conditions with $R_{\varepsilon}=-1$ for FeP04 steel are the following [4]: the cyclic strength coefficient $K^{\prime}=838 \mathrm{MPa}$ and the cyclic strain hardening exponent $n^{\prime}=0.22$ All fatigue tests were performed under force control, by imposing a constant value of the nominal load ratio $R=0$ with load amplitudes $P_{a}=6$ and $7 \mathrm{kN}$ (which corresponded to the nominal amplitude of normal stresses $\sigma_{a}=100$ and $117 \mathrm{MPa}$ before the crack initiation). The test frequency ranged from 13 to $15 \mathrm{~Hz}$. The specimens were characterized by double symmetric lateral notches with a notch root radius ranging from $0.2 \mathrm{~mm}$ to $10 \mathrm{~mm}$ (Fig. 1). The theoretical stress concentration factor in the specimen under tension $K_{t}=9.61,4.30,3.23$, and 1.85 was estimated with use of the model [5]. In a number of fatigue tests, fatigue crack initiation and propagation phases were controlled by means of an optical microscope $(\times 20)$.

Microstructure and Fatigue Crack path in FeP04 Steel. Steel FeP04 can be easily subjected to cold working, it belongs to ferritic steels. Since amount of carbon in ferrite is low, ferrite properties are very similar to those of pure iron $\alpha$. The considered steel is

C D. ROZUMEK, 2008

ISSN 0556-17IX. Проблемьт прочности, 2008, № 1 
applied for deep drawing. Fig. $2 b$ shows microstructure of FeP04 steel, containing the ferrite (light) and numerous non-metallic inclusions. The structure exhibits a distinct rolling texture. Numerous non-metallic inclusions, mainly chains of oxides about $1 \mu \mathrm{m}$ (black) are visible against the background of long ferrite grains. The coalesced cementite can be seen at the ferrite grain boundaries in Fig. 2b. Figure 2 presents the surface of a specimen tested under loading $P_{a}=6 \mathrm{kN}$ and with the radius of notch root $\rho=0.2 \mathrm{~mm}$ after $N_{f}=22,700$ cycles to failure. Different magnifications were chosen so as to present a path of the main crack, about $0.9 \mathrm{~mm}$ in length (Fig. 2a). Figure $2 b$ shows a crack course taken from Fig. 2 a, for magnification $\times 2000$, in order to analyze the crack growth. Here, transcrystalline cracks through the grains of $\alpha$-phase are dominating, but cracks along the grain boundaries are also observed. The main cracks propagate in direction perpendicular to the loading action, but secondary cracks are also visible.

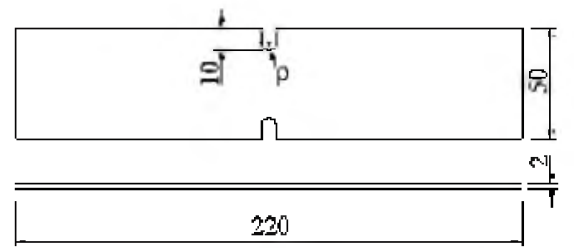

Fig. 1. Geometry of the specimen characterized by notches.

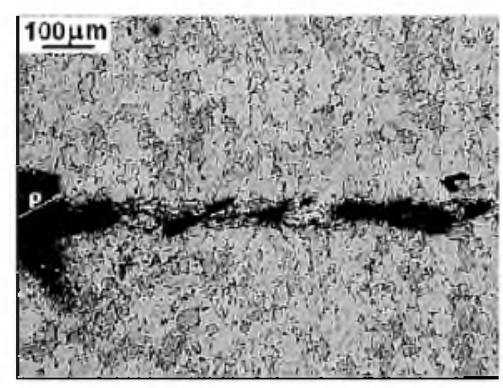

a

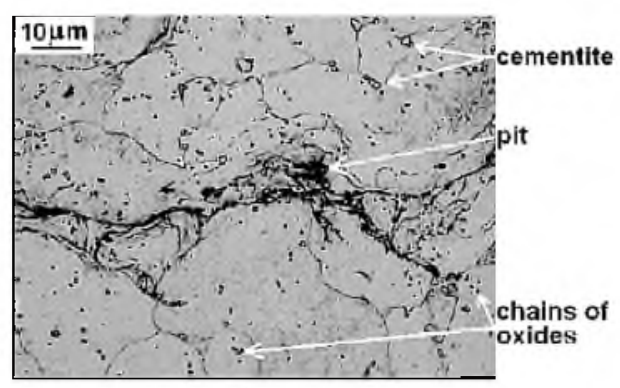

b

Fig. 2. The fatigue crack path in the FeP04 steel, magnification: (a) $\times 200$; (b) $\times 2000$.

Initiation and growth of short (secondary) fatigue cracks can be seen in grains or at the boundaries of $\alpha$-phase (Fig. 2b). In most cases, the secondary cracks growing in the ferrite grains are blocked in the places where coalesced cementite and the non-metallic inclusions are present. Further characteristic of the considered cracks, including short cracks, is that they grow in different directions in relation to the specimen axis. The main cracks grow in the planes of the maximum normal stresses. There are short lateral cracks inclined to the main crack at the angle of 30 and $40^{\circ}$. Because of high plasticity of the tested material, ductile cracking is observed. It is characterized by voids (black fields in Fig. 2) after the material stratification observed in the cracking path. Stress concentration and intensification of plastic flow occur around the voids. In Fig. 2a, asymmetric pits can be found, which are caused by the mean loading and located in the perpendicular plane or at a certain angle (up to $30^{\circ}$ ) to direction of the external loading action. Stratification of the material can be seen at a certain distance from the main crack. The fatigue crack growth rate in the ferrite grains is dependent on the stress value. Similar crack growth was observed in case of specimens with the notch root radii $\rho=125,2.5$, and $10 \mathrm{~mm}$.

Test Results and Analysis. In double logarithmic coordinates, Fig. 3 gives the number of cycles to initiation and to failure for different notch root radii. The cracks (of minimal observable crack length about 0.1 to $0.2 \mathrm{~mm}$ ) initiated at the same time on the left and on the right of the slot. As seen from curves crack length $a$ vs number of cycles 
$N$ in Fig. 4, after changing the notch root radii $\rho$ from 0.2 to $10 \mathrm{~mm}$, fatigue life increases. It is evident that with the highest radii, the initiation phase, which depends on the stress conditions at the notch tip, prevails.

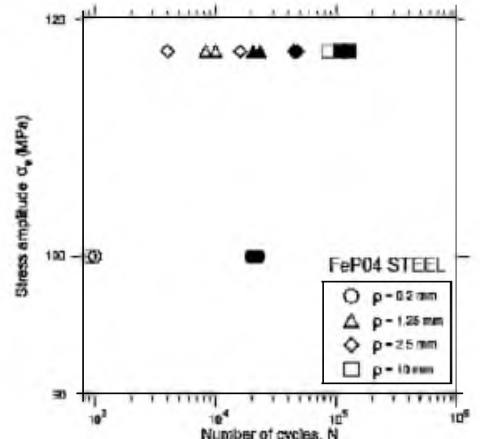

Fig. 3

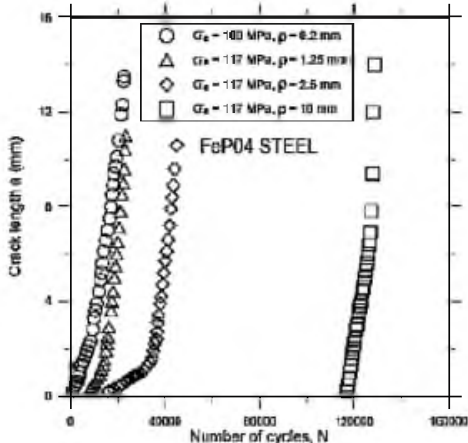

Fig. 4

Fig. 3. Comparison between crack initiation points (open symbols) and final failures (solid symbols), as a function of different values of the notch root radius.

Fig. 4. Dependencies of fatigue crack length versus number of cycles for different values of the notch root radius.

On the basis of the results presented in Figs. 3 and 4 it can be stated that with the increase of notch root radii the number of cycles to initiation and failure of specimens also rises. Fig. 5a shows the fatigue crack growth rate $d a / d N$ versus $\Delta K$ relations under different notch root radii and load amplitude conditions. For different notches, under $P_{a}=7 \mathrm{kN}$, with the notch radius change (from $\rho=1.25$ to $\rho=10 \mathrm{~mm}$ in the range $76<\Delta K<100 \mathrm{MPa} \cdot \mathrm{m}^{1 / 2}$ ) the crack growth rate increases. Figure $5 \mathrm{~b}$ shows the fatigue crack growth rate $d a / d N$ versus $\Delta J$ relations. These relations show almost the same tendency as the $d a / d N$ versus $\Delta K$ relations. In Fig. 5 and for $\rho=0.2$ and $10 \mathrm{~mm}$, at the initial stage of the crack growth, there is the influence of plasticity visible (displacement of symbols $\bigcirc$ to the right in relation to symbols $\square$ ).

In the elastic-plastic range, stresses and strains were calculated by means of the finite element FRANC2D software. In the models six-node triangular elements were used. The test results shown in Fig. 5a were described by the Paris equation [6] and in Fig. 5b by the modified equation

$$
d a / d N=B(\Delta K)^{n} \quad \text { and } \quad d a / d N=B_{1}(\Delta J)^{n_{1}},
$$

where $\Delta J=J_{\max }-J_{\min }, B, B_{1}$ and $n, n_{1}$ are empirical coefficients. The $\Delta J$ value in Eq. (1) was calculated by using the following relationship [7], which is for slightly hardening and cyclically stable materials

$$
\Delta J=\frac{\Delta K^{2}}{E}+\pi Y^{2} \frac{\Delta \sigma \Delta \varepsilon_{p}}{\sqrt{n^{\prime}}} a,
$$

where $\Delta K=K_{\max }-K_{\min }=Y \Delta \sigma \sqrt{\pi\left(a+a_{0}\right)}$ and $\Delta \sigma$ is the stress range corresponding to the plastic strain range $\Delta \varepsilon_{p}$, both ranges evaluated ahead of the notch (stress and strain fields by FEM for slot were calculated the near crack tip about 0.1 to $0.5 \mathrm{~mm}-$ local approach), $a_{0}$ is notch depth, $Y$ is correction factor [4], $Y=1.12+0.203\left(2\left(a+a_{0}\right) / w\right)-$ $1.197\left(2\left(a+a_{0}\right) / w\right)^{2}+1.93\left(2\left(a+a_{0}\right) / w\right)^{3}$, and $w$ is specimen width. The empirical coefficients $B, B_{1}$ and $n, n_{1}$ occurring in Eq. (1) and the correlation coefficients $r$ were 
$\mathrm{T}$ a b 1 e 1

Coefficients $B$ and $n$ in Eq. (1) and Correlation Index $r$ for the Curves in Fig. 5

\begin{tabular}{|c|c|c|c|c|c|c|}
\hline $\begin{array}{c}\text { Figures, } \\
\text { graphs }\end{array}$ & $\begin{array}{c}B, \\
\mathrm{~m} /(\mathrm{MPa} \sqrt{\mathrm{m}})^{n}, \text { cycle }\end{array}$ & $n$ & $r$ & $\begin{array}{c}B_{1}, \\
\mathrm{~m} /(\mathrm{MPa} \sqrt{\mathrm{m}})^{n_{1}}, \text { cycle }\end{array}$ & $n_{1}$ & $r_{1}$ \\
\hline $5 \mathrm{a}-1,5 \mathrm{~b}-1$ & $2.377 \cdot 10^{-10}$ & 1.808 & 0.89 & $1.950 \cdot 10^{-6}$ & 0.453 & 0.89 \\
\hline $5 \mathrm{a}-2,5 \mathrm{~b}-2$ & $1.722 \cdot 10^{-12}$ & 2.954 & 0.82 & $2.636 \cdot 10^{-6}$ & 0.467 & 0.87 \\
\hline $5 \mathrm{a}-3,5 \mathrm{~b}-3$ & $3.069 \cdot 10^{-14}$ & 3.802 & 0.94 & $5.346 \cdot 10^{-6}$ & 0.889 & 0.94 \\
\hline $5 \mathrm{a}-4,5 \mathrm{~b}-4$ & $2.917 \cdot 10^{-9}$ & 1.166 & 0.74 & $1.050 \cdot 10^{-6}$ & 0.304 & 0.80 \\
\hline
\end{tabular}

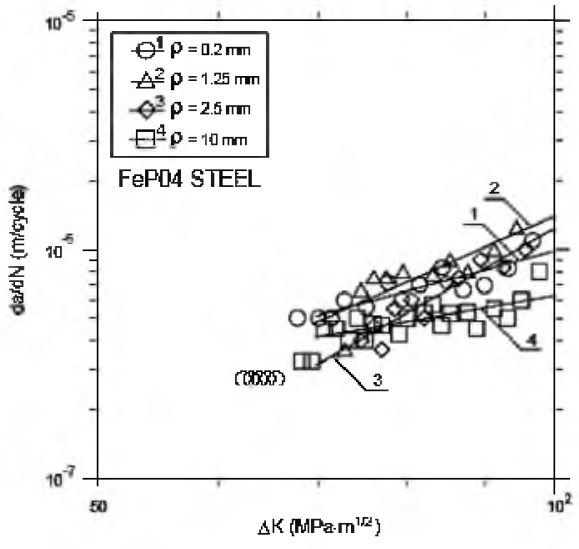

a

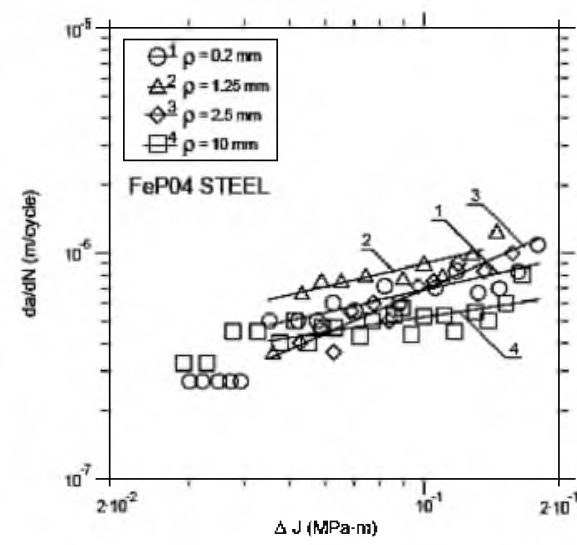

b

Fig. 5. Crack growth rate behavior $d a / d N$ versus $\Delta K$ (a) and $d a / d N$ versus $\Delta J$ (b)

determined with the least square method for a confidence level $\alpha=0.05$ and they were shown in Table 1.

Conclusions. In the considered material, ductile cracking is observed and in such cracking voids occur after material lamination. At the specimen fractures, it was possible to find transcrystalline cracks through the grains of $\alpha$-phase and cracks along the grain boundaries. The notch root radius rises together with increase number of cycles to initiation and failure of specimens. After comparison of the influence of notches with $\rho=0.2$ and $10 \mathrm{~mm}$ on the crack growth rate, at the initial cracking period larger plastic were observed for $\rho=0.2$ (see displacement of symbols in Fig. 5).

1. S. Kocanda, Fatigue Failure of Metals, Sijthoff \& Noordhoff Int. Publishers (1985), p. 441.

2. D. Rozumek amd E. Macha, A Description of Fatigue Crack Growth in Elasto-Plastic Materials under Proportional Bending with Torsion [in Polish], Opole University of Technology (2006), p. 198.

3. P. Lazzarin, R. Tovo, and G. Meneghetti, Int. J. Fatigue, 19, 647-657 (1997).

4. D. Rozumek, E. Macha, P. Lazzarin, and G. Meneghetti, J. Theor. Appl. Mech., 44, 127-137 (2006).

5. A. Thum, C. Petersen, and O. Swenson, Verformung, Spannung, und Kerbwirkung, VDI (1960).

6. P. C. Paris and H. Tada, Int. J. Fracture, 11, 1070-1072 (1975).

7. D. Rozumek, Proc. 12th Int. Conf. on Experimental Mechanics (ICEM12), Politecnico di Bari (2004), pp. 275-276.

Received 28.06. 2007 